\title{
HLA-E Polymorphism Determines Susceptibility to BK Virus Nephropathy after Living-Donor Kidney Transplant
}

\author{
Hana Rohn ${ }^{1, *}$, Rafael Tomoya Michita ${ }^{2,3}{ }^{10}$, Sabine Schramm ${ }^{2}$, Sebastian Dolff ${ }^{1}$, Anja Gäckler ${ }^{4}$, \\ Johannes Korth ${ }^{4}\left(\mathbb{0}\right.$, Falko M. Heinemann ${ }^{2}$, Benjamin Wilde ${ }^{4}$, Mirko Trilling ${ }^{5} \oplus$, Peter A. Horn ${ }^{2}$, \\ Andreas Kribben ${ }^{4}$, Oliver Witzke ${ }^{1}$ and Vera Rebmann ${ }^{2}$ (D) \\ 1 Department of Infectious Diseases, West German Centre for Infectious Diseases (WZI), University Hospital \\ Essen, University Duisburg-Essen, 45147 Essen, Germany \\ 2 Institute for Transfusion Medicine, University Hospital Essen, University Duisburg-Essen, \\ 45147 Essen, Germany \\ 3 Post-Graduation Program in Genetics and Molecular Biology, Genetics Department, Universidade Federal \\ do Rio Grande do Sul (UFRGS), Porto Alegre 91501-970, Brazil \\ 4 Department of Nephrology, University Hospital Essen, University Duisburg-Essen, 45147 Essen, Germany \\ 5 Institute for Virology, University Hospital Essen, University Duisburg-Essen, 45147 Essen, Germany \\ * Correspondence: hana.rohn@uk-essen.de; Tel.: +49 201723 3394; Fax: +49 2017233393
}

Received: 22 June 2019; Accepted: 6 August 2019; Published: 7 August 2019

\begin{abstract}
Human leukocyte antigen (HLA)-E is important for the regulation of anti-viral immunity. $\mathrm{BK}$ polyomavirus $(\mathrm{BKPyV})$ reactivation after kidney transplant is a serious complication that can result in BKPyV-associated nephropathy (PyVAN) and subsequent allograft loss. To elucidate whether HLA-E polymorphisms influence BKPyV replication and nephropathy, we determined the HLA-E genotype of 278 living donor and recipient pairs. A total of 44 recipients suffered from BKPyV replication, and 11 of these developed PyVAN. Homozygosity of the recipients for the HLA-E*01:01 genotype was associated with the protection against PyVAN after transplant $(p=0.025$, OR 0.09, CI [95\%] 0.83-4.89). Considering the time course of the occurrence of nephropathy, recipients with PyVAN were more likely to carry the HLA-E*01:03 allelic variant than those without PyVAN (Kaplan-Meier analysis $p=0.03$; OR $=4.25$; CI (95\%) 1.11-16.23). Our findings suggest that a predisposition based on a defined HLA-E genotype is associated with an increased susceptibility to develop PyVAN. Thus, assessing HLA-E polymorphisms may enable physicians to identify patients being at an increased risk of this viral complication.
\end{abstract}

Keywords: BK virus; polyomavirus; nephropathy; human leukocyte antigen-E; kidney transplantation

\section{Introduction}

Human leukocyte antigen (HLA)-E belongs to the non-classical major histocompatibility complex (MHC) class Ib molecules located on chromosome 6p21.3. In terms of function, HLA-E is special within the immune system because it acts as a key player exhibiting regulatory functions both in innate and adaptive immune responses [1].

HLA-E predominantly acts as an indicator for "missing-self" by continuously presenting peptides derived from signal sequences from HLA class Ia molecules. Infected or transformed cells, which have silenced HLA-I expression to evade from canonical CD8 T-cell recognition, do not produce such signal peptides. In absence of the signal peptides, HLA-E is not stabilized and does not reach the cell surface. NK cells sense the absence of HLA-E and become activated. Recently it became apparent that HLA-E can also bind and present antigenic peptides derived from pathogens such as HIV, hepatitis B and C 
viruses as well as cytomegalovirus [2], a fact implying that HLA-E plays an important role in anti-viral immunity mediated by T cells [3,4]. Being the cognate ligand for the C-type lectin CD94/NKG2 receptor family, HLA-E enables natural killer (NK) cells and cytotoxic T lymphocytes to monitor cell integrity because it is recognized by either the inhibitory CD94/NKG2A or the activating CD94/NKG2C receptor [5-7]. Moreover, HLA-E can be recognized by the stimulatory $\alpha / \beta$ T-cell receptor (TCR) expressed on the CD8+ T cells, resulting in cytotoxic elimination of target cells presenting foreign peptides presented by HLA-E [8].

In contrast to the highly polymorphic HLA-A, HLA-B, or HLA-C molecules, HLA-E exhibits fewer allelic variants [9]. To date, only 27 HLA-E alleles have been reported, most of which are found in neglectable frequencies in the population or do not encode functional proteins at all [10]. The two most prevalent allotypes in the Caucasian population are HLA-E*01:01 (HLA-E107R) and HLA-E*01:03 (HLA-E107G), which are found with nearly equal frequencies [11]. Although the two corresponding proteins only differ by an arginine (HLA-E*01:01) or a glycine (HLA-E*01:03) at position 107 [12], functional differences have been reported. HLA-E*01:03 has been reported to exhibit a higher affinity for available peptides, and for this reason its cell surface expression is significantly increased compared to HLA-E*01:01 [11,13]. Studies of viral diseases have shown that the various HLA-E genotypes affect a clinical outcome [14-16].

Little is known about the relevance of HLA-E concerning viral infection and reactivation after solid organ transplant. Viruses are the leading cause of infections and mortality after transplant. In particular, the reactivation of otherwise mostly subclinical, opportunistic viruses from pre-existing latency reservoirs is clinically relevant during immunosuppression. BK polyomavirus (BKPyV), a small non-enveloped double-stranded DNA virus, has emerged as one of the most challenging pathogens after kidney transplant, causing severe allograft dysfunction and graft loss. Approximately $80 \%$ to $95 \%$ of the human population are persistently infected with BKPyV; the infection mostly occurs in healthy adults [17-19]. However, the immunosuppression necessary after kidney transplant enables the virus to reactivate. Viral replication can occur in as many as 60\% of recipients [20], and can progress to the most severe form of BKPyV invasive kidney disease, polyomavirus-associated nephropathy (PyVAN).

PyVAN is linked to kidney malfunction and rejection, with a significant risk of allograft loss in as many as $60 \%$ of the cases [19,21-23]. Unfortunately, no direct antiviral treatment is approved for $\mathrm{BKPyV}$ replication, and the current recommendation for BKPyV management and PyVAN treatment is restricted to a reduction of immunosuppression, leading to a substantial risk of acute rejection. Little is known about the pathogenesis of $\mathrm{BKPyV}$, and it is not clear which factors determine the clinical course of PyVAN. From a clinical perspective, the identification of genetic biomarkers that influence the course of BKPyV infection may allow early risk stratification to prevent the progression of PyVAN.

Thus, considering the functional differences between the HLA-E allelic variants, we hypothesized that these allelic variants may affect the clinical occurrence and onset of PyVAN after kidney transplant and may serve as a prognostic parameter for determining which patients are at risk.

\section{Materials and Methods}

\subsection{Study Population, BKPyV and PyVAN Screening}

A total of 278 living-donor kidney transplant recipients and their 278 corresponding donors from the living-donor kidney program at the University Hospital Essen, Germany, were enrolled in this retrospective study. Transplant procedures were performed between 2005 and 2017. Informed consent was obtained from all patients in accordance with the Declaration of Helsinki, and the local ethics committee approved the study (approval number 12-5312-BO). All patients underwent regular follow-up examinations. An exclusion criterion was treatment with an mTOR inhibitor, since clinical data indicate that the use of mTOR-based immunosuppressive regimens may be protective against BKPyV replication [22,24-26]. The following data were collected: demographic and transplant-related 
characteristics of recipients and donors (Table 1), the occurrence of BKPyV, and the occurrence of biopsy-proven PyVAN.

Table 1. Patient characteristics at baseline.

\begin{tabular}{|c|c|c|c|c|}
\hline & A & B & $\mathrm{C}$ & \\
\hline & Total & $\begin{array}{l}\text { HLA-E*01:03 } \\
\text { Carrier\# }\end{array}$ & $\begin{array}{l}\text { HLA-E*01:03 } \\
\text { Non-Carrier }\end{array}$ & $\begin{array}{l}p \text {-Value B } \\
\text { vs. C }\end{array}$ \\
\hline Donor & $N=278$ & $N=211$ & $N=67$ & \\
\hline Sex (men/women) & $115 / 163$ & $89 / 122$ & $26 / 41$ & $0.67^{\mathrm{a}}$ \\
\hline Age $(y) \pm S D$ & $51.41 \pm 10.03$ & $51.99 \pm 10.06$ & $43.30 \pm 9.83$ & $0.10^{b}$ \\
\hline Recipient & $\mathbf{N}=278$ & $\mathbf{N}=198$ & $\mathbf{N}=80$ & \\
\hline Sex (men/women) & $162 / 116$ & $116 / 82$ & $46 / 34$ & $0.87^{\mathrm{a}}$ \\
\hline Age $(y) \pm S D$ & $41.06 \pm 15.43$ & $40.46 \pm 15.42$ & $42.53 \pm 15.47$ & $0.32^{b}$ \\
\hline \multicolumn{5}{|c|}{ KTx Related Variables } \\
\hline HLA A, B mismatches, mean \pm SD & $1.97 \pm 1.14$ & $1.83 \pm 1.1$ & $2.31 \pm 1.17$ & $0.002 * * \mathrm{~b}$ \\
\hline HLA-DR mismatch, mean \pm SD & $1.12 \pm 0.62$ & $1.09 \pm 0.60$ & $1.19 \pm 0.66$ & $0.22^{b}$ \\
\hline \multicolumn{5}{|c|}{ Panel of Antibodies (\%) } \\
\hline $0 \%$ & 244 & 172 & 72 & $0.55^{\mathrm{a}}$ \\
\hline $1-10 \%$ & 14 & 9 & 5 & $0.55^{\mathrm{a}}$ \\
\hline $10-50 \%$ & 14 & 12 & 2 & $0.36^{a}$ \\
\hline$>50 \%$ & 6 & 5 & 1 & $0.68^{a}$ \\
\hline $\begin{array}{l}\text { Cold ischemia time, median, } \\
\text { in minutes (range) }\end{array}$ & $134.99 \pm 48.90$ & $136.07 \pm 48.63$ & $131.32 \pm 48.86$ & $0.57^{b}$ \\
\hline $\begin{array}{l}\text { Warm ischemia time, median, } \\
\text { in minutes (range) }\end{array}$ & $19.97 \pm 6.87$ & $19.38 \pm 5.84$ & $21.46 \pm 8.83$ & $0.057^{b}$ \\
\hline
\end{tabular}

\begin{tabular}{|c|c|c|c|c|}
\hline \multicolumn{5}{|c|}{ Immunosuppressive Therapy } \\
\hline $\begin{array}{l}\text { ATG-based induction therapy, } \\
\text { yes/no }\end{array}$ & $13 / 265$ & 9/189 & $4 / 76$ & $1^{\mathrm{a}}$ \\
\hline CNI administration, yes/no & $278 / 0$ & $198 / 0$ & $80 / 0$ & nd \\
\hline MMF co-administration, yes/no & $260 / 18$ & $189 / 9$ & $75 / 5$ & $0.55^{\mathrm{a}}$ \\
\hline Steroid co-administration, yes/no & $278 / 0$ & $198 / 0$ & $80 / 0$ & nd \\
\hline \multicolumn{5}{|c|}{ PyVAN and CMV } \\
\hline PyVAN, yes/no & $11 / 267$ & $11 / 187$ & $0 / 80$ & 0.031 *a \\
\hline CMV positive recipient & $159 / 119$ & $116 / 82$ & $43 / 37$ & $0.46^{\mathrm{a}}$ \\
\hline CMV positive donor & $177 / 101$ & $128 / 70$ & $49 / 31$ & $0.59^{\mathrm{a}}$ \\
\hline CMV Infection, yes/no & $38 / 240$ & $32 / 166$ & $6 / 74$ & $0.057^{\mathrm{a}}$ \\
\hline $\begin{array}{c}\text { PyVAN and CMV infection, } \\
\text { yes/no }\end{array}$ & $3 / 275$ & 3/195 & $0 / 80$ & $0.27^{\mathrm{a}}$ \\
\hline $\begin{array}{l}\text { PyVAN or CMV infection vs. no } \\
\text { PyVAN and no CMV infection }\end{array}$ & $46 / 232$ & $40 / 158$ & $6 / 74$ & $0.01^{\mathrm{a}}$ \\
\hline
\end{tabular}

y: years; HLA: human leukocyte antigen; ATG: antithymocyte globulin; CNI: calcineurin inhibitor; MMF: mycophenolate mofetil; KTx: kidney transplant; PyVAN: BK polyomavirus associated nephropathy; CMV: cytomegalovirus; nd: not determined; SD: standard deviation. ${ }^{a}$ Fisher's exact test; ${ }^{b}$ Mann-Whitney U test; \# HLA E*01:03 carrier: HLA E*01:03/01:03 and HLA E*01:03/01:01genotype; HLA E*01:03 non-carrier: HLA $\mathrm{E}^{*} 01: 01 / 01: 01$ genotype. ${ }^{*} p<0.05,{ }^{* *} p<0.01$. 
Screening for BKPyV replication after transplant evolved during the course of the study in accordance with the introduction of new clinical guidelines. Initially, only patients with graft dysfunction were tested for BKPyV replication. Starting from 2010, the screening for BKPyV replication after kidney transplant was performed according to the 2009 clinical practice guideline Kidney Disease: Improving Global Outcomes (KDIGO). In addition to scheduled BKPyV screening, patients' serum was tested for BKPyV replication once allograft dysfunction was detected. All samples were analyzed by quantitative real-time polymerase chain reaction (RT-PCR) with a lower limit of quantification of 400 copies per milliliter. BKPyV reactivation was defined as viremia when RT-PCR detected BKPyV DNA in patients' serum.

Occurrence of PyVAN was assessed during the first three years after transplantation. PyVAN was diagnosed, if found in at least one kidney biopsy specimen judged positive by an experienced renal pathologist according to standard criteria [27]. Kidney biopsies were performed only upon clinical indication of PyVAN, like evidence of graft dysfunction or high levels of BKPyV viremia. Besides BKPyV, cytomegalovirus (CMV) represents an important viral pathogen that negatively affects allograft survival [28-31]. We have previously reported that the polymorphism of HLA-E is associated with CMV infection after kidney transplantation [16]. To evaluate possible interactions between these two viral infections with respect to the HLA-E polymorphism, we determined the rate of CMV infections for the present cohort as defined by international recommendations [32]. Standard induction immunosuppression consisted of treatment with a basiliximab-based regimen (which blocks the IL-2 receptor CD25) and a calcineurin inhibitor (CNI) in combination with steroids and an antiproliferative drug (mycophenolic acid or azathioprine).

\subsection{HLA-E Genotyping}

Recipients and corresponding donors were typed for HLA-E with a sequence-specific primer-polymerase chain reaction (SSP-PCR) method as described previously [33,34]. Genomic DNA was isolated from buffy-coats of peripheral blood using QIAamp ${ }^{\circledR}$ DNA Blood Mini Kit (QIAGEN GmbH, D-40724 Hilden, Germany). The SSP-PCR method was performed with the following conditions: $50 \mathrm{ng}$ of genomic DNA was amplified in a final reaction volume of $10 \mu \mathrm{L}$ containing $3 \mu \mathrm{L}$ PCR Master Mix (Olerup ${ }^{\circledR}$ SSP AB, Stockholm, Sweden), 0.6 units of Taq DNA Polymerase (QIAGEN GmBH), 15 pmol of detection primers and 15 pmol of each positive control primer. The initial denaturation of the sequence-specific products was performed for $2 \mathrm{~min}$ at $94{ }^{\circ} \mathrm{C}$, followed by a two stage PCR program: 10 cycles of $10 \mathrm{~s}$ at $94^{\circ} \mathrm{C}$ and $20 \mathrm{~s}$ at $65^{\circ} \mathrm{C}$, as well as 20 relaxed cycles of $10 \mathrm{~s}$ at $94^{\circ} \mathrm{C}$, of $1 \mathrm{~min}$ at $61^{\circ} \mathrm{C}$ and of $30 \mathrm{~s}$ at $72{ }^{\circ} \mathrm{C}$. HLA-E alleles were identified at the resolution level of the second field. Human growth hormone was used as a positive control for PCR amplification. HLA-E genotype distributions in the two groups matched expectations according to the Hardy-Weinberg equilibrium.

\subsection{Prediction of HLA-E Affinity for BKPyV Derived Peptides}

The non-classical HLA-E molecule exhibits preferential binding to a highly conserved set of nonameric signal peptides derived from leader sequences of other HLA-class I molecules. However, HLA-E is also able to present pathogen-derived antigens [2], hence antigens derived from CMV, human immunodeficiency virus (HIV) and other pathogens give rise to peptides, which are loaded onto HLA-E molecules $[14,35]$. To our knowledge, HLA-E restricted peptides encoded by BKPyV have not been described to date. To identify peptide sequences derived from BKPyV antigens that may bind to HLA-E with high affinity and thus potentially representing immunogenic T-cell epitopes, we applied the machine-learning bioinformatics algorithm NetMHC 4.0 (http.//www.cbs.dtu.dk/ services/NetMHC/index.php) [36,37]. NetMHC 4.0 is a method trained on both binding affinity and eluted ligand data. The algorithm uses an allele-specific approach, whereby separate predictors are trained for each MHC allele; the input to the model is the peptide of interest (in our case derived from BKPyV) [36]. The following BKPyV-derived antigens were assessed for HLA-E binding potential: large-T and small-T antigen, the major capsid proteins VP1 and VP2, and the agnoprotein. In order to 
compare the affinities of putative BKPyV-derived peptides predicted by the NetMHC 4.0 algorithm, functionally well-defined HLA-E binding peptides derived from the classical HLA class I molecule HLA-G and HLA-Cw*3, the heath shock protein 60, CMV proteins (pUL40, pUL18, pUL83, and pUL123), and two other pathogen-derived peptides (viz., the HIV gag protein and mycobacterium tuberculosis enoyl-[acyl-carrier-protein] reductase) were also determined [8,38-41]. We only took "strong binding peptides" as defined by the NetMHC 4.0 algorithm into consideration. Strong binding peptides are defined by an affinity threshold of $50,000 \mathrm{nM}$ as well as a percentile rank assignment within $<0.5$ being a predicted affinity compared to a set of 400,000 random natural peptides. Solely the HLA-E*01:01 allele is present in NetMHC 4.0; thus we were able to determine the peptide affinity for this allelic variant only.

\subsection{Statistical Analysis}

Statistical analyses were performed using the SPSS 21.0 software (IBM corp. Released 2012, IBM SPSS Statistic for Windows, Armonk, NY, USA). Baseline characteristics of donors and recipients were compared with two-sided Fisher's exact test or the Wilcoxon rank-sum test, as appropriate. The contribution of allelic variants as risk factors for PyVAN was evaluated by Fisher's exact test. Joint genotype analysis was performed by Mantel-Haenszel test. The occurrence of PyVAN was estimated by the Kaplan-Meier method, and estimates were compared with the log-rank test. A two-sided $p$-value of 0.05 or lower was considered statistically significant.

\section{Results}

\subsection{HLA-E*01:01 May Be Able to Present Peptide Sequences Derived from BKPyV}

We were able to identify BKPyV-derived peptides that may be presented by the HLA-E*01:01 allelic variant using the machine-learning bioinformatics algorithm NetMHC 4.0 (National Institute of Allergy and Infectious Diseases, National Institutes of Health, Bethesda, MD, USA). Tables 2-5 contains the identified high and moderate affinity peptide sequences derived from BKPyV antigens (large-T and small-t antigen, VP1, VP2 and agnoprotein) which may be presented to immune effector cells by HLA-E*01:01.

Table 2. High and moderate affinity peptide sequences derived from BK polyomavirus (BKPyV) large $\mathrm{T}$ antigen and small $\mathrm{t}$ antigen that may be presented by the HLA-E*01:01 allelic variant as identified by the machine-learning bioinformatics algorithm NetMHC4.0. Position: residue number (starting from $0)$; peptide: amino acid sequence of the potential ligand.

\begin{tabular}{cccc}
\hline \multicolumn{4}{c}{ Large-T and Small-t Antigen } \\
\hline Position & Peptide & $\mathbf{1}-\log 50 k(a f f)$ & Affinity (nM) \\
\hline 416 & NVPKRRYWL & 0.202 & 5619.93 \\
\hline 568 & RILQSGMTL & 0.173 & 7666.40 \\
\hline 454 & PMERLTFEL & 0.165 & 8432.78 \\
\hline 557 & SLQNSEFLL & 0.160 & 8874.14 \\
\hline 570 & LQSGMTLLL & 0.150 & 9850.58 \\
\hline
\end{tabular}


Table 3. High and moderate affinity peptide sequences derived from BKPyV major capsid protein VP1 that may be presented by the HLA-E*01:01 allelic variant as identified by the machine-learning bioinformatics algorithm NetMHC 4.0. Position: residue number (starting from 0); peptide: amino acid sequence of the potential ligand.

\begin{tabular}{cccc}
\hline \multicolumn{4}{c}{ BK Polyomavirus Major Capsid Protein VP1 } \\
\hline Position & Peptide & $\mathbf{1}$ - $\mathbf{l o g} 50 k(a f f)$ & Affinity (nM) \\
\hline 18 & KEPVQVPKL & 0.186 & 6716.19 \\
\hline 237 & TNTATTVLL & 0.142 & $10,773.00$ \\
\hline 297 & NPYPISFLL & 0.139 & $11,067.54$ \\
\hline
\end{tabular}

Table 4. High affinity peptide sequences derived from BKPyV major capsid protein VP2 that may be presented by the HLA-E*01:01 allelic variant as identified by the machine-learning bioinformatics algorithm NetMHC 4.0. Position: residue number (starting from 0); peptide: amino acid sequence of the potential ligand.

\begin{tabular}{cccc}
\hline \multicolumn{4}{c}{ BK Polyomavirus Major Capsid Protein VP2 } \\
\hline Position & Peptide & 1 - log50k(aff) & Affinity(nM) \\
\hline 292 & WMLPLLLGL & 0.152 & 9685.81 \\
\hline
\end{tabular}

Table 5. High and moderate affinity peptide sequences derived from BKPyV agnoprotein that may be presented by the HLA-E*01:01 allelic variations as identified by the machine-learning bioinformatics algorithm NetMHC 4.0. Position: residue number (starting from 0); peptide: amino acid sequence of the potential ligand.

\begin{tabular}{cccc}
\hline \multicolumn{4}{c}{ BK Polyomavirus Agnoprotein } \\
\hline Position & Peptide & 1 - log50k(aff) & Affinity (nM) \\
\hline 46 & SXXPESVMF & 0.139 & $11,081.08$ \\
\hline 52 & VMFCEPKNL & 0.139 & $11,162.18$ \\
\hline
\end{tabular}

The affinities of putative nonameric BKPyV-derived peptides predicted by the NetMHC 4.0 algorithm were compared to the HLA-E-binding peptide repertoire reported in the literature [8,38-41] (Supplementary Table S1a-i). Table 6 summarizes the results of the binding affinities of the identified peptide motifs with the highest affinity as predicted by the NetMHC 4.0 algorithm.

Leader peptide sequences of HLA-Cw*3, the CMV homologue pUL40 [35], and HLA-G molecules had the highest predicted binding affinity to HLA-E. The predicted binding affinities of the BKPyV-derived antigens ranged between these and other well-characterized peptide sequences. It is noteworthy that the primary anchor residues among the leader peptides sequences are largely conserved at the canonical position 2 Met (methionine) and position 9 Leu (leucine) [6,9]. Three out of four identified BKPyV HLA-E binding motifs have Leu at position 9 and the BK polyomavirus major capsid protein VP2 has also Met at position 2. 
Table 6. The high affinity peptide motifs reported in the literature and derived from different self or foreign antigens as well as BKPyV-derived antigens that may be presented by HLA-E*01:01 allelic variations identified by the machine-learning bioinformatics algorithm NetMHC 4.0.

\begin{tabular}{cccc}
\hline Derived from & Peptide & 1 - log50k(aff) & Affinity (nM) \\
\hline Human leukocyte antigen-Cw*3 & VMAPRTLIL & 0.589 & 85.69 \\
CMV protein pUL40 & VMAPRTLIL & 0.589 & 85.69 \\
Human leukocyte antigen-G & VMAPRTLFL & 0.564 & 112.12 \\
Mycobacterium tuberculosis & RLPAKAPLL & 0.547 & 134.77 \\
enoyl-[acyl-carrier-protein] reductase [NADH] & VLPHETRLL & 0.330 & 1405.23 \\
CMV phosphorylated matrix protein pp65 (UL83) & VLPH & 1887.52 \\
CMV immediate-early protein 1 (pUL123) & VMLAKRPLI & 0.303 & 2530.17 \\
Human heat shock protein 60 (hsp60) & QMRPVSRVL & 0.276 & 2614.63 \\
CMV protein pUL18 & SEPQCNPLL & 0.273 & 5619.93 \\
BK polyomavirus large-T and small-t antigen & NVPKRRYWL & 0.202 & 6716.19 \\
BK polyomavirus major capsid protein VP1 & KEPVQVPKL & 0.186 & 7728.11 \\
Human immunodeficiency virus 1 Gag protein & RMYSPVSIL & 0.173 & 9685.81 \\
BK polyomavirus major capsid protein VP2 & WMLPLLLGL & 0.152 & 11081.08 \\
BK polyomavirus agnoprotein & SXXPESVMF & 0.139 & \\
\hline
\end{tabular}

Methionine at amino acid positions 2 and leucine at position 9 amino acid have been described to be of functional relevance for HLA-E binding [9,35,42]. Peptide: amino acid sequence of the potential ligand.

\subsection{HLA-E*01:01 Homozygosity Exerts Protection against PyVAN}

HLA-E allelic frequencies in our cohort were similar among recipients (HLA-E*01:01 294 of 556 [52.9\%]; HLA-E*01:03 262 of 556 [47.1\%]) and donors (HLA-E*01:01 282 of 556 [50.7\%]; HLA-E*01:03 274 of $556[49.3 \%]$ ). No other HLA-E variants were detected. The observed allelic distribution of HLA-E was in accordance with expectations indicated by the Hardy-Weinberg equilibrium.

In total, 44 recipients (15.8\%) tested positive for BKPyV viremia; 23 of these exhibited high levels of BKPyV viremia ( $>10^{4}$ copies per milliliter). Eleven BKPyV-positive recipients had at least one biopsy-proven PyVAN during the first three years after kidney transplant. Three out of the eleven patients experienced CMV replication prior to the development of a BK virus-associated nephropathy. All three patients, in which the CMV replication preceded the BK virus-associated nephropathy, were HLA-E*01:03 carriers.

With respect to HLA-E genotypes, there was no association of HLA-E genotypes of the donor and the occurrence of PyVAN (Table 7).

However, the recipient HLA-E*01:01 homozygous state was associated with protection against PyVAN, ( $p=0.025$, odds ratio [OR] 0.09, 95\% confidence interval [CI] 0.83-4.89; Table 7). By combining BK virus nephropathy with the occurrence of CMV replication, the same observation was made (Table 8). 
Table 7. Genotype distribution of allele frequencies of HLA-E polymorphism in living-donor kidney transplant recipients (A) and corresponding donors (B) with respect to BK polyomavirus nephropathy (PyVAN).

\begin{tabular}{|c|c|c|c|c|c|}
\hline $\begin{array}{l}\text { (A) Recipient } \\
\text { HLA-E genotype }\end{array}$ & $\begin{array}{l}\text { PyVAN } \\
\mathbf{N}=11\end{array}$ & $\begin{array}{l}\text { No PyVAN } \\
\mathrm{N}=267\end{array}$ & $p$-Value & OR & $95 \% \mathrm{CI}$ \\
\hline 01:03/01:03 & $3(27.3 \%)$ & $61(22.8 \%)$ & 0.73 & 1.26 & $0.33-4.92$ \\
\hline 01:01/01:03 & $8(72.7 \%)$ & $126(47.2 \%)$ & 0.10 & 2.98 & $0.77-11.50$ \\
\hline 01:01/01:01 & $0(0 \%)$ & $80(30 \%)$ & 0.025 * & 0.09 & $0.005-1.59$ \\
\hline \multicolumn{6}{|c|}{ Allele Frequencies } \\
\hline 01:03 & 14 & 248 & \multirow{2}{*}{0.11} & \multirow{2}{*}{2.02} & \multirow{2}{*}{$0.83-4.89$} \\
\hline 01:01 & 8 & 286 & & & \\
\hline $\begin{array}{c}\text { (B) Donor } \\
\text { HLA-E genotype }\end{array}$ & $\begin{array}{l}\text { PyVAN } \\
\mathrm{N}=11\end{array}$ & $\begin{array}{c}\text { No PyVAN } \\
\mathbf{N}=267\end{array}$ & $p$-Value & OR & CI $(95 \%)$ \\
\hline 01:03/01:03 & $1(9.1 \%)$ & $62(23.2 \%)$ & 0.27 & 0.33 & $0.04-2.63$ \\
\hline 01:01/01:03 & $9(81.8 \%)$ & $139(52.1 \%)$ & 0.052 & 4.14 & 0.89-19.55 \\
\hline 01:01/01:01 & $1(9.1 \%)$ & $66(24.7 \%)$ & 0.24 & 0.3 & $0.04-2.42$ \\
\hline \multicolumn{6}{|c|}{ Allele Frequencies } \\
\hline 01:03 & 11 & 263 & \multirow{2}{*}{0.77} & \multirow{2}{*}{1.1} & \multirow{2}{*}{$0.47-2.7$} \\
\hline 01:01 & 10 & 271 & & & \\
\hline
\end{tabular}

Table 8. Genotype distribution of allele frequencies of HLA-E polymorphism in living-donor kidney transplant recipients (A) and corresponding donors (B) with respect to BK polyomavirus nephropathy (PyVAN) or cytomegalovirus (CMV) infection.

\begin{tabular}{|c|c|c|c|c|c|}
\hline $\begin{array}{c}\text { (A) Recipient } \\
\text { HLA-E genotype }\end{array}$ & $\begin{array}{c}\text { PyVAN or } \\
\text { CMV Infection } \\
\quad \mathrm{N}=46\end{array}$ & $\begin{array}{c}\text { No PyVAN and no } \\
\text { CMV Infection } \\
\text { N }=267\end{array}$ & $p$-Value & OR & $95 \% \mathrm{CI}$ \\
\hline 01:03/01:03 & $12(26.1 \%)$ & $52(22.4 \%)$ & 0.57 & 1.22 & $0.59-2.53$ \\
\hline 01:01/01:03 & $28(60.9 \%)$ & $106(45.7 \%)$ & 0.07 & 1.85 & $0.96-3.53$ \\
\hline 01:01/01:01 & $6(13.0 \%)$ & $74(31.9 \%)$ & $0.012 *$ & 0.32 & $0.13-0.79$ \\
\hline \multicolumn{6}{|c|}{ Allele Frequencies } \\
\hline 01:03 & 52 & 210 & \multirow{2}{*}{0.052} & \multirow{2}{*}{1.57} & \multirow{2}{*}{$1.00-2.47$} \\
\hline 01:01 & 40 & 254 & & & \\
\hline $\begin{array}{l}\text { (B) Donor HLA-E } \\
\text { genotype }\end{array}$ & $\begin{array}{c}\text { PyVAN or } \\
\text { CMV Infection } \\
\text { N }=46\end{array}$ & $\begin{array}{c}\text { No PyVAN and no } \\
\text { CMV Infection } \\
\text { N }=267\end{array}$ & $p$-Value & OR & CI $(95 \%)$ \\
\hline 01:03/01:03 & $12(9.1 \%)$ & $51(22.0 \%)$ & 0.44 & 1.33 & $0.64-2.79$ \\
\hline 01:01/01:03 & $26(81.8 \%)$ & $122(52.6 \%)$ & 0.75 & 1.17 & $0.62-2.22$ \\
\hline 01:01/01:01 & $8(9.1 \%)$ & $59(25.4 \%)$ & 0.34 & 0.62 & $0.27-1.39$ \\
\hline \multicolumn{6}{|c|}{ Allele Frequencies } \\
\hline 01:03 & 50 & 224 & \multirow{2}{*}{0.31} & \multirow{2}{*}{1.3} & \multirow{2}{*}{$0.81-1.99$} \\
\hline 01:01 & 42 & 240 & & & \\
\hline
\end{tabular}

Considering the time course of PyVAN occurrence, the results of Kaplan-Meier analysis combined with those of the log-rank test (Figure 1) indicate that recipients carrying the HLA-E*01:03 allele were 
at significantly higher risk of PyVAN during the first three years after kidney transplant as compared to non-carriers $(p=0.03 ; \mathrm{OR}=4.25 ; 95 \%$ CI 1.11-16.23). Of note, all 11 recipients with PyVAN carried at least one HLA-E*01:03 allele.

With regard to HLA-E polymorphism of donor or recipient, we found no association with the occurrence or level of BKPyV viremia.
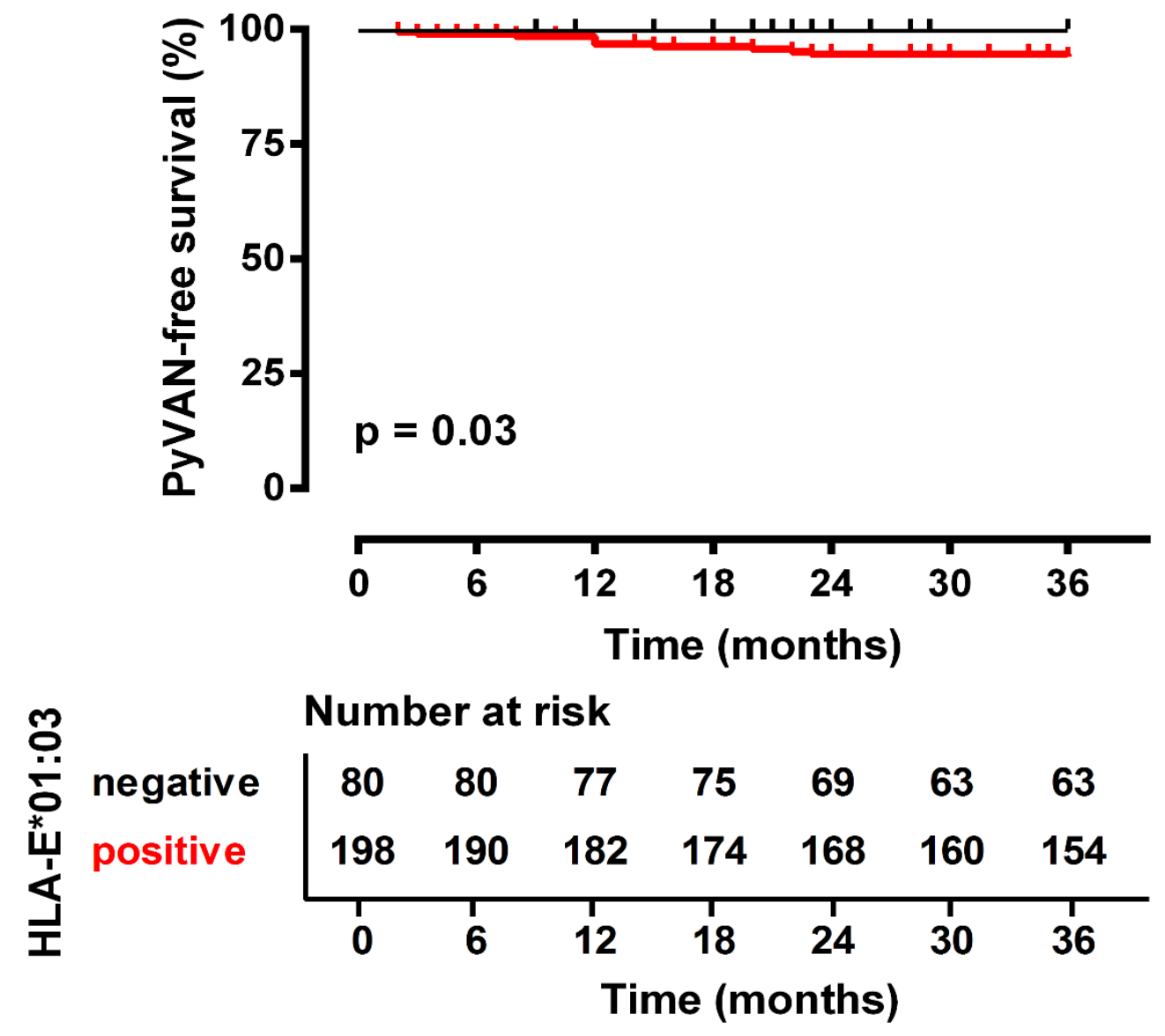

Figure 1. Association between the PyVAN-free survival and the HLA-E*01:03 carrier status of the transplant recipient during the first three years after living-donor kidney transplant. Recipients carrying the HLA-E*01:03 allelic variant were significantly more susceptible to develop PyVAN.

\section{Discussion}

To gain insights into BKPyV replication after kidney transplant, we evaluated the role of HLA-E genotypes in a large cohort of living kidney transplant pairs. To our knowledge, this is the first study demonstrating that the HLA-E polymorphism is associated with the pathogenesis of PyVAN after kidney transplant. Our study indicates that considering the time course of PyVAN occurrence, the prevalence of the HLA-E*01:03 allelic variant among living-donor kidney transplant recipients with PyVAN was significantly higher than that among recipients with no PyVAN. In addition, the homozygous status of the HLA-E*01:01 allele in the recipient is associated with protection against PyVAN.

This finding is in line with those of the previous studies attributing the distinctive susceptibility of patients with the HLA-E polymorphism to various viral infections. Recently, we found that HLA-E*01:03 carrier status is associated with cytomegalovirus infection after kidney transplant. Similarly, Schulte et al. reported that the homozygous HLA-E*01:01 genotype exerts a protective effect against Hepatitis C virus [16,43].

Despite the highly negative impact of BKPyV on patient and allograft survival, little is known about the immunology of BKPyV infection. Patients with a high BKPyV viral load are particularly 
likely to develop PyVAN and to experience allograft loss. The implementation of regular BKPyV monitoring has become a useful tool allowing the detection of patients at risk of PyVAN. The current treatment strategy against sustained BKPyV replication is a stepwise reduction or modification of the immunosuppression so that the endogenous immune control of the virus is gradually restored, thereby potentially preventing the development of PyVAN. However, this approach must be balanced against the increasing risk of allograft rejection and is not always successful. The identification of additional predictive markers indicating which patients are especially prone to PyVAN is therefore important. In combination with viral molecular monitoring, the analysis of specific immune biomarkers can make a decisive contribution in supporting the surveillance and treatment of kidney transplant recipients at risk of PyVAN. This approach will allow new preventive measures, alternative treatment strategies, and patient-tailored immunosuppression. As is the case for cytomegalovirus infection, clinical evidence indicate that the use of mTOR-based immunosuppressive regimens may be protective against BKPyV replication $[24,26]$.

Only three patients had a CMV and BKPyV co-replication in this cohort. In such cases of combined BK virus nephropathy and CMV replication, it became evident that both events were associated with HLA-E*01:03 recipient carrier status. However, we cannot exclude that CMV additionally promotes development of BK virus nephropathy. After transplantation, CMV DNAemia has been associated with a general state of over-immunosuppression, potentially increasing risk of complications elicited by opportunistic infections [44]. Interestingly, however, Reischig et al. recently reported that the risk of BK viremia as well as PyVAN is decreased in patients who experienced CMV DNAemia [45]. At this stage, it is impossible to clarify if CMV affected the occurrence and/or severity of PyVAN in the three cases.

The host immune response is essential in controlling the viral carrier state. Increasing amount of evidences suggest that the immunomodulatory molecule HLA-E plays an important role in viral immunity. HLA-E is broadly expressed at low levels, and its expression can be up-regulated during cellular stress, such as viral infection. HLA-E is special within the immune system because it not only exhibits regulatory functions in innate and adaptive immune responses, but also promotes activating as well as inhibitory signals. These differences in HLA-E functions lead to differential effects on T- and NK-cell activity and depend on three determinants: (i) the nature of the presented peptides, (ii) the cognate receptor repertoire, and (iii) the expression level of the HLA-E alleles. HLA-E preferentially binds leader peptides sequences derived from classical HLA-class I molecules. In addition to presenting self-antigens, HLA-E can bind several nonameric peptides of viral origin [35,46,47]. It has been shown that the binding repertoire of HLA-E is broad and that the diversity of HLA-E binding motifs can considerably differ from the leader peptides sequences of classical HLA-class I molecules $[35,41]$. To date no study has shown that HLA-E binds BKPyV-specific peptides, however, the bioinformatics algorithm NetMHC $4.0[36,37]$ has identified several peptide sequences derived from BKPyV early antigens (large-T and small-t) and late antigens (VP1 and VP2) that may bind to HLA-E with high affinity. The predicted binding affinity of the BKPyV-derived antigens in our study falls between the values of the leader peptide sequences of HLA-G and HLA-Cw $* 3$ molecules and the HIV Gag-derived peptide. Of note the HIV Gag-peptide is a NetMHC predicted epitope being a homologous to the Simian immunodeficiency virus (SIV) Gag-derived peptide, which has recently been shown to comprise one of the two supertopes recognized by $100 \%$ of rhesus macaques vaccinated against SIV [48].

The presented peptide is of great importance because the interaction between the HLA-E-peptide and the cognate activating CD94/NKG2C or inhibitory CD94/NKG2A receptors expressed on the surface of NK cells and certain T cells has been described as peptide-sensitive [49,50]. Analysis of amino acid preferences for HLA-E binding at each anchor position demonstrated a clear preference for methionine (Met) at positions 2 and a leucine (Leu) at position 9 [9,35,42]. Three of the four BKPyV-derived peptide sequences identified in this study have a Leu at position 9, and one also has a Met at position 2, rendering HLA-E binding rather likely. Intriguingly, the activating receptor CD94/NKG2C is found less frequently and binds to the ligand HLA-E with lower affinity and stricter peptide selectivity than the inhibitory CD94/NKG2A receptor [51,52]. HLA-presented peptides are also of importance for the 
regulation of adaptive NK-cells expressing the activating CD94/NKG2C receptor [53-58]. Recently, Horowitz $\mathrm{A}$ et al. demonstrated that the binding affinity of the presented HLA-E peptide by affection of HLA-E cell surface expression impacts on the NK cell education through its influence on HLA-E cell surface disposition. As a result of enhanced HLA-E expression, NK cell education is dominated by CD94/NKG2A, whereas in individuals with peptide motifs with low binding affinity to HLA-E, NK cell education is dominated by inhibitory killer-cell immunoglobulin-like receptors (KIRs) [59]. Moreover, viral infections may imprint on the CD94/NKG2 receptor compartment, as has been shown for cytomegalovirus and Hepatitis $\mathrm{C}$ virus [60]. Studies using mice infected with polyomavirus (PyV) found that CD94/NKG2A expression is rapidly induced on antiviral CD8+ T-cells, thereby reducing the cytotoxic activity of PyV-specific CD8+ T-cells [61-64]. Since the HLA-E*01:03 variant consistently shows higher cell surface expression compared to HLA-E*01:01, the baseline engagement of the inhibitory CD94/NKG2A might even be higher during viral infection, thus promoting viral immune escape. With regard to HLA-E*01:01, herein described potential HLA-E*01:01-specific T cell epitopes might be recognized by $\mathrm{CD} 8+\mathrm{T}$ cells leading to immune activation.

In our cohort, the recipient homozygous genotype HLA-E*01:01 was associated with protection against PyVAN, whereas HLA-E*01:03 carrier status in recipients was associated with an increased risk of PyVAN after kidney transplant. In the context of transplant, it is necessary to take recipient- and donor-derived genetic factors that may influence the outcome of viral infection into account. Although the two HLA-E alleles differ only by a single amino acid, this subtle difference has important functional implications, because HLA- $E^{*} 01: 03$ proteins exhibit consistently higher surface expression than does HLA-E*01:01 [11,65]. This discrepancy in cell surface expression suggests differences in the effective engagement of the CD94/NKG2A or C receptors expressed on NK and T cells. With a dominant presence of the inhibitory CD94/NKG2A receptor on effector cells, the HLA-E*01:03 variant may be related to a more pronounced dampening of inhibitory receptor responses and, thus, to insufficient immune control of viruses like CMV and BKPyV. Conversely, the presence of the homozygous HLA-E*01:01 variant may result in a lower probability of interaction with its cognate inhibitory CD94/NKG2A receptor, a condition resulting in increased susceptibility to lysis mediated by effector cells.

However, this single-center analysis has its limitations due to the retrospective nature of the study and the low incidence of PyVAN in our cohort, which did not allow multivariate analysis. Additionally, our conclusions on the effects of HLA-E polymorphism on BKPyV viremia are limited due to the changes in the screening procedure for BKPyV viremia during study period. Nevertheless, our results provide a rational for future prospective clinical studies and detailed mechanistic analyses.

\section{Conclusions}

The data presented here suggest that the HLA-E genetic predisposition of the recipients may influence the susceptibility to PyVAN. Thus, testing for the HLA-E polymorphism may enable physicians to determine which patients are at risk of PyVAN.

Supplementary Materials: The following are available online at http://www.mdpi.com/2073-4409/8/8/847/s1, Table S1a-i: High- and moderate peptide sequences that may be presented by HLA-E*01:01 allelic variations (as identified by the machine-learning bioinformatics algorithm NetMHC 4.0) deriving from (a) CMV Protein UL-40, (b) CMV Protein UL-18, (c) CMV Phosphorylated matrix protein pp65 (UL83), (d) CMV immediate-early protein 1 (UL123), (e) Human leukocyte antigen-G, (f) Human leukocyte antigen-Cw*3, (g) Human heat shock protein (hsp60), (h) Human immundeficency virus 1 Gag protein, (i) Mycobacterium tuberculosis Enoyl -[acyl-carrier-protein]-reductase [NADH].

Author Contributions: H.R., P.A.H., A.K., O.W., V.R.: conceived and designed research. H.R., R.T.M., S.S.: performed the experiments. F.M.H.: contributed reagents. S.D., A.G., B.W., J.K.: collected and provided clinical data. H.R., R.T.M., S.D., M.T., V.R.: interpreted data and H.R., R.T.M., A.G., B.W., J.K., V.R.: performed statistical analysis. H.R. and V.R.: wrote the initial draft. H.R., R.T.M., S.S., S.D., A.G., M.T., B.W., J.K., F.M.H., P.A.H., A.K., O.W., V.R.: read and approved the final article.

Funding: We acknowledge support by the Open Access Publication Fund of the University Duisburg Essen. H.R. was supported by the "Programm zur internen Forschungsförderung Essen" (IFORES) Research fellowship program of the University Duisburg-Essen Medical School". R.M.T. was supported by the "Coordenação de 
Aperfeicoamento de Pessoal de Nível Superior (CAPES) Foundation, Ministry of Education of Brazil, Brasília-DF Brazil (99999.000124/2016-08)", the "Conselho Nacional de Desenvolvimento Científico e Tecnológico" (CNPq) Foundation, Ministry of Science and Technology of Brazil, Brasília-DF Brazil (142475/2015-7) and by the "Deutsche Akademische Austauschdienst" (DAAD) Scholarship of the German Federal Ministry of Education and Research. O.W. is supported by an unrestricted grant of the Rudolf-Ackermann-Stiftung (Stiftung für Klinische Infektiologie).

Acknowledgments: We thank the donors and recipients for participating in this study and Florence M. Witte, (Bluegrass Editorial Services Team, Lexington, Kentucky, USA) for editorial assistance.

Conflicts of Interest: The authors declare no conflict of interest.

\section{References}

1. Sullivan, L.C.; Clements, C.S.; Rossjohn, J.; Brooks, A.G. The major histocompatibility complex class Ib molecule HLA-E at the interface between innate and adaptive immunity. Tissue Antigens 2008, 72, 415-424. [CrossRef] [PubMed]

2. Joosten, S.A.; Sullivan, L.C.; Ottenhoff, T.H. Characteristics of HLA-E Restricted T-Cell Responses and Their Role in Infectious Diseases. J. Immunol. Res. 2016, 2016, 2695396. [CrossRef] [PubMed]

3. Romagnani, C.; Pietra, G.; Falco, M.; Mazzarino, P.; Moretta, L.; Mingari, M.C. HLA-E-restricted recognition of human cytomegalovirus by a subset of cytolytic T lymphocytes. Hum. Immunol. 2004, 65, 437-445. [CrossRef] [PubMed]

4. Petrie, E.J.; Clements, C.S.; Lin, J.; Sullivan, L.C.; Johnson, D.; Huyton, T.; Heroux, A.; Hoare, H.L.; Beddoe, T.; Reid, H.H.; et al. CD94-NKG2A recognition of human leukocyte antigen (HLA)-E bound to an HLA class I leader sequence. J. Exp. Med. 2008, 205, 725-735. [CrossRef] [PubMed]

5. Lauterbach, N.; Voorter, C.E.; Tilanus, M.G. Molecular typing of HLA-E. Methods Mol. Biol. 2012, 882, $143-158$. [CrossRef] [PubMed]

6. Lee, N.; Llano, M.; Carretero, M.; Ishitani, A.; Navarro, F.; Lopez-Botet, M.; Geraghty, D.E. HLA-E is a major ligand for the natural killer inhibitory receptor CD94/NKG2A. Proc. Natl. Acad. Sci. USA 1998, 95, 5199-5204. [CrossRef] [PubMed]

7. Romagnani, C.; Pietra, G.; Falco, M.; Millo, E.; Mazzarino, P.; Biassoni, R.; Moretta, A.; Moretta, L.; Mingari, M.C. Identification of HLA-E-specific alloreactive T lymphocytes: A cell subset that undergoes preferential expansion in mixed lymphocyte culture and displays a broad cytolytic activity against allogeneic cells. Proc. Natl. Acad. Sci. USA 2002, 99, 11328-11333. [CrossRef] [PubMed]

8. Garcia, P.; Llano, M.; de Heredia, A.B.; Willberg, C.B.; Caparros, E.; Aparicio, P.; Braud, V.M.; Lopez-Botet, M. Human $\mathrm{T}$ cell receptor-mediated recognition of HLA-E. Eur. J. Immunol. 2002, 32, 936-944. [CrossRef]

9. Braud, V.; Jones, E.Y.; McMichael, A. The human major histocompatibility complex class Ib molecule HLA-E binds signal sequence-derived peptides with primary anchor residues at positions 2 and 9. Eur. J. Immunol. 1997, 27, 1164-1169. [CrossRef]

10. Felicio, L.P.; Porto, I.O.; Mendes-Junior, C.T.; Veiga-Castelli, L.C.; Santos, K.E.; Vianello-Brondani, R.P.; Sabbagh, A.; Moreau, P.; Donadi, E.A.; Castelli, E.C. Worldwide HLA-E nucleotide and haplotype variability reveals a conserved gene for coding and 3' untranslated regions. Tissue Antigens 2014, 83, 82-93. [CrossRef]

11. Ulbrecht, M.; Couturier, A.; Martinozzi, S.; Pla, M.; Srivastava, R.; Peterson, P.A.; Weiss, E.H. Cell surface expression of HLA-E: Interaction with human beta2-microglobulin and allelic differences. Eur. J. Immunol. 1999, 29, 537-547. [CrossRef]

12. Strong, R.K.; Holmes, M.A.; Li, P.; Braun, L.; Lee, N.; Geraghty, D.E. HLA-E allelic variants. Correlating differential expression, peptide affinities, crystal structures, and thermal stabilities. J. Biol. Chem. 2003, 278, 5082-5090. [CrossRef] [PubMed]

13. Pyo, C.W.; Williams, L.M.; Moore, Y.; Hyodo, H.; Li, S.S.; Zhao, L.P.; Sageshima, N.; Ishitani, A.; Geraghty, D.E. HLA-E, HLA-F, and HLA-G polymorphism: Genomic sequence defines haplotype structure and variation spanning the nonclassical class I genes. Immunogenetics 2006, 58, 241-251. [CrossRef] [PubMed]

14. Lajoie, J.; Hargrove, J.; Zijenah, L.S.; Humphrey, J.H.; Ward, B.J.; Roger, M. Genetic variants in nonclassical major histocompatibility complex class I human leukocyte antigen (HLA)-E and HLA-G molecules are associated with susceptibility to heterosexual acquisition of HIV-1. J. Infect. Dis. 2006, 193, 298-301. [CrossRef] [PubMed] 
15. Zidi, I.; Laaribi, A.B.; Bortolotti, D.; Belhadj, M.; Mehri, A.; Yahia, H.B.; Babay, W.; Chaouch, H.; Zidi, N.; Letaief, A.; et al. HLA-E polymorphism and soluble HLA-E plasma levels in chronic hepatitis B patients. Hla 2016, 87, 153-159. [CrossRef] [PubMed]

16. Guberina, H.; da Silva Nardi, F.; Michita, R.T.; Dolff, S.; Bienholz, A.; Heinemann, F.M.; Wilde, B.; Trilling, M.; Horn, P.A.; Kribben, A.; et al. Susceptibility of HLA-E*01:03 Allele Carriers to Develop Cytomegalovirus Replication After Living-Donor Kidney Transplantation. J. Infect. Dis. 2018, 217, 1918-1922. [CrossRef] [PubMed]

17. Hirsch, H.H.; Randhawa, P. AST Infectious Diseases Community of Practice. BK polyomavirus in solid organ transplantation-Guidelines from the American Society of Transplantation Infectious Diseases Community of Practice. Clin. Transplant. 2019. [CrossRef]

18. Hirsch, H.H.; Randhawa, P. AST Infectious Diseases Community of Practice. BK polyomavirus in solid organ transplantation. Am. J. Transplant. 2013, 13 (Suppl. 4), 179-188. [CrossRef] [PubMed]

19. Babel, N.; Volk, H.D.; Reinke, P. BK polyomavirus infection and nephropathy: The virus-immune system interplay. Nat. Rev. Nephrol. 2011, 7, 399-406. [CrossRef]

20. Bressollette-Bodin, C.; Coste-Burel, M.; Hourmant, M.; Sebille, V.; Andre-Garnier, E.; Imbert-Marcille, B.M. A prospective longitudinal study of BK virus infection in 104 renal transplant recipients. Am. J. Transplant. 2005, 5, 1926-1933. [CrossRef]

21. Korth, J.; Widera, M.; Dolff, S.; Guberina, H.; Bienholz, A.; Brinkhoff, A.; Anastasiou, O.E.; Kribben, A.; Dittmer, U.; Verheyen, J.; et al. Impact of low-level BK polyomavirus viremia on intermediate-term renal allograft function. Transpl. Infect. Dis. 2018, 20, e12817. [CrossRef]

22. Berger, S.P.; Sommerer, C.; Witzke, O.; Tedesco, H.; Chadban, S.; Mulgaonkar, S.; Qazi, Y.; de Fijter, J.W.; Oppenheimer, F.; Cruzado, J.M.; et al. Two-year outcomes in de novo renal transplant recipients receiving everolimus-facilitated calcineurin inhibitor reduction regimen from TRANSFORM study. Am. J. Transplant. 2019. [CrossRef]

23. Budde, K.; Lehner, F.; Sommerer, C.; Reinke, P.; Arns, W.; Eisenberger, U.; Wuthrich, R.P.; Muhlfeld, A.; Heller, K.; Porstner, M.; et al. Five-year outcomes in kidney transplant patients converted from cyclosporine to everolimus: The randomized ZEUS study. Am. J. Transplant. 2015, 15, 119-128. [CrossRef] [PubMed]

24. Jouve, T.; Rostaing, L.; Malvezzi, P. Place of mTOR inhibitors in management of BKV infection after kidney transplantation. J. Nephropathol. 2016, 5, 1-7. [CrossRef] [PubMed]

25. Korth, J.; Anastasiou, O.E.; Verheyen, J.; Dickow, J.; Sertznig, H.; Frericks, N.; Bleekmann, B.; Kribben, A.; Brinkhoff, A.; Wilde, B.; et al. Impact of immune suppressive agents on the BK-Polyomavirus non coding control region. Antivir. Res. 2018, 159, 68-76. [CrossRef]

26. Acott, P.; Babel, N. BK virus replication following kidney transplant: Does the choice of immunosuppressive regimen influence outcomes? Ann. Transplant. 2012, 17, 86-99. [CrossRef]

27. Kopp, J.B. Banff Classification of Polyomavirus Nephropathy: A New Tool for Research and Clinical Practice. J. Am. Soc. Nephrol. 2018, 29, 354-355. [CrossRef]

28. Kotton, C.N.; Kumar, D.; Caliendo, A.M.; Huprikar, S.; Chou, S.; Danziger-Isakov, L.; Humar, A. The Third International Consensus Guidelines on the Management of Cytomegalovirus in Solid-organ Transplantation. Transplantation 2018, 102, 900-931. [CrossRef]

29. Sagedal, S.; Hartmann, A.; Nordal, K.P.; Osnes, K.; Leivestad, T.; Foss, A.; Degre, M.; Fauchald, P.; Rollag, H. Impact of early cytomegalovirus infection and disease on long-term recipient and kidney graft survival. Kidney Int. 2004, 66, 329-337. [CrossRef]

30. Sagedal, S.; Nordal, K.P.; Hartmann, A.; Sund, S.; Scott, H.; Degre, M.; Foss, A.; Leivestad, T.; Osnes, K.; Fauchald, P.; et al. The impact of cytomegalovirus infection and disease on rejection episodes in renal allograft recipients. Am. J. Transplant. 2002, 2, 850-856. [CrossRef]

31. Petersen, P.; Schneeberger, H.; Schleibner, S.; Illner, W.D.; Hofmann, G.O.; Land, W. Positive donor and negative recipient cytomegalovirus status is a detrimental factor for long-term renal allograft survival. Transpl. Int. 1994, 7 (Suppl. 1), S336-S338. [CrossRef] [PubMed]

32. Ljungman, P.; Boeckh, M.; Hirsch, H.H.; Josephson, F.; Lundgren, J.; Nichols, G.; Pikis, A.; Razonable, R.R.; Miller, V.; Griffiths, P.D.; et al. Definitions of Cytomegalovirus Infection and Disease in Transplant Patients for Use in Clinical Trials. Clin. Infect. Dis. 2017, 64, 87-91. [CrossRef] [PubMed] 
33. Grimsley, C.; Kawasaki, A.; Gassner, C.; Sageshima, N.; Nose, Y.; Hatake, K.; Geraghty, D.E.; Ishitani, A. Definitive high resolution typing of HLA-E allelic polymorphisms: Identifying potential errors in existing allele data. Tissue Antigens 2002, 60, 206-212. [CrossRef] [PubMed] 
34. Guberina, H.; Rebmann, V.; Wagner, B.; da Silva Nardi, F.; Dziallas, P.; Dolff, S.; Bienholz, A.; Wohlschlaeger, J.; Bankfalvi, A.; Heinemann, F.M.; et al. Association of high HLA-E expression during acute cellular rejection and numbers of HLA class I leader peptide mismatches with reduced renal allograft survival. Immunobiology 2017, 222, 536-543. [CrossRef] [PubMed]

35. Kraemer, T.; Celik, A.A.; Huyton, T.; Kunze-Schumacher, H.; Blasczyk, R.; Bade-Doding, C. HLA-E: Presentation of a Broader Peptide Repertoire Impacts the Cellular Immune Response-Implications on HSCT Outcome. Stem Cells Int. 2015, 2015, 346714. [CrossRef] [PubMed]

36. Andreatta, M.; Nielsen, M. Gapped sequence alignment using artificial neural networks: Application to the MHC class I system. Bioinformatics 2016, 32, 511-517. [CrossRef] [PubMed]

37. Nielsen, M.; Lundegaard, C.; Worning, P.; Lauemoller, S.L.; Lamberth, K.; Buus, S.; Brunak, S.; Lund, O. Reliable prediction of T-cell epitopes using neural networks with novel sequence representations. Protein Sci. 2003, 12, 1007-1017. [CrossRef]

38. Heatley, S.L.; Pietra, G.; Lin, J.; Widjaja, J.M.; Harpur, C.M.; Lester, S.; Rossjohn, J.; Szer, J.; Schwarer, A.; Bradstock, K.; et al. Polymorphism in human cytomegalovirus UL40 impacts on recognition of human leukocyte antigen-E (HLA-E) by natural killer cells. J. Biol. Chem. 2013, 288, 8679-8690. [CrossRef]

39. Michaelsson, J.; Teixeira de Matos, C.; Achour, A.; Lanier, L.L.; Karre, K.; Soderstrom, K. A signal peptide derived from hsp60 binds HLA-E and interferes with CD94/NKG2A recognition. J. Exp. Med. 2002, 196, 1403-1414. [CrossRef]

40. Nattermann, J.; Nischalke, H.D.; Hofmeister, V.; Kupfer, B.; Ahlenstiel, G.; Feldmann, G.; Rockstroh, J.; Weiss, E.H.; Sauerbruch, T.; Spengler, U. HIV-1 infection leads to increased HLA-E expression resulting in impaired function of natural killer cells. Antivir. Ther. 2005, 10, 95-107.

41. Walters, L.C.; Harlos, K.; Brackenridge, S.; Rozbesky, D.; Barrett, J.R.; Jain, V.; Walter, T.S.; O'Callaghan, C.A.; Borrow, P.; Toebes, M.; et al. Pathogen-derived HLA-E bound epitopes reveal broad primary anchor pocket tolerability and conformationally malleable peptide binding. Nat. Commun. 2018, 9, 3137. [CrossRef] [PubMed]

42. Schulte, D.; Vogel, M.; Langhans, B.; Kramer, B.; Korner, C.; Nischalke, H.D.; Steinberg, V.; Michalk, M.; Berg, T.; Rockstroh, J.K.; et al. The HLA-E(R)/HLA-E(R) genotype affects the natural course of hepatitis C virus $(\mathrm{HCV})$ infection and is associated with HLA-E-restricted recognition of an HCV-derived peptide by interferon-gamma-secreting human CD8(+) T cells. J. Infect. Dis. 2009, 200, 1397-1401. [CrossRef] [PubMed]

43. Fishman, J.A. Infection in Organ Transplantation. Am. J. Transplant. 2017, 17, 856-879. [CrossRef] [PubMed]

44. Reischig, T.; Kacer, M.; Hes, O.; Machova, J.; Nemcova, J.; Lysak, D.; Jindra, P.; Pivovarcikova, K.; Kormunda, S.; Bouda, M. Cytomegalovirus prevention strategies and the risk of BK polyomavirus viremia and nephropathy. Am. J. Transplant. 2019. [CrossRef] [PubMed]

45. Celik, A.A.; Kraemer, T.; Huyton, T.; Blasczyk, R.; Bade-Doding, C. The diversity of the HLA-E-restricted peptide repertoire explains the immunological impact of the Arg107Gly mismatch. Immunogenetics 2016, 68, 29-41. [CrossRef] [PubMed]

46. Lampen, M.H.; Hassan, C.; Sluijter, M.; Geluk, A.; Dijkman, K.; Tjon, J.M.; de Ru, A.H.; van der Burg, S.H.; van Veelen, P.A.; van Hall, T. Alternative peptide repertoire of HLA-E reveals a binding motif that is strikingly similar to HLA-A2. Mol. Immunol. 2013, 53, 126-131. [CrossRef]

47. Hansen, S.G.; Wu, H.L.; Burwitz, B.J.; Hughes, C.M.; Hammond, K.B.; Ventura, A.B.; Reed, J.S.; Gilbride, R.M.; Ainslie, E.; Morrow, D.W.; et al. Broadly targeted CD8(+) T cell responses restricted by major histocompatibility complex E. Science 2016, 351, 714-720. [CrossRef]

48. Llano, M.; Lee, N.; Navarro, F.; Garcia, P.; Albar, J.P.; Geraghty, D.E.; Lopez-Botet, M. HLA-E-bound peptides influence recognition by inhibitory and triggering CD94/NKG2 receptors: Preferential response to an HLA-G-derived nonamer. Eur. J. Immunol. 1998, 28, 2854-2863. [CrossRef]

49. Stevens, J.; Joly, E.; Trowsdale, J.; Butcher, G.W. Peptide binding characteristics of the non-classical class Ib MHC molecule HLA-E assessed by a recombinant random peptide approach. BMC Immunol. 2001, 2, 5. [CrossRef]

50. Miller, J.D.; Weber, D.A.; Ibegbu, C.; Pohl, J.; Altman, J.D.; Jensen, P.E. Analysis of HLA-E peptide-binding specificity and contact residues in bound peptide required for recognition by CD94/NKG2. J. Immunol. 2003, 171, 1369-1375. [CrossRef] 
51. Vales-Gomez, M.; Reyburn, H.T.; Erskine, R.A.; Lopez-Botet, M.; Strominger, J.L. Kinetics and peptide dependency of the binding of the inhibitory NK receptor CD94/NKG2-A and the activating receptor CD94/NKG2-C to HLA-E. EMBO J. 1999, 18, 4250-4260. [CrossRef]

52. Kaiser, B.K.; Barahmand-Pour, F.; Paulsene, W.; Medley, S.; Geraghty, D.E.; Strong, R.K. Interactions between NKG2x immunoreceptors and HLA-E ligands display overlapping affinities and thermodynamics. J. Immunol. 2005, 174, 2878-2884. [CrossRef]

53. Guma, M.; Angulo, A.; Vilches, C.; Gomez-Lozano, N.; Malats, N.; Lopez-Botet, M. Imprint of human cytomegalovirus infection on the NK cell receptor repertoire. Blood 2004, 104, 3664-3671. [CrossRef]

54. Guma, M.; Budt, M.; Saez, A.; Brckalo, T.; Hengel, H.; Angulo, A.; Lopez-Botet, M. Expansion of CD94/NKG2C+ NK cells in response to human cytomegalovirus-infected fibroblasts. Blood 2006, 107, 3624-3631. [CrossRef]

55. Hammer, Q.; Ruckert, T.; Borst, E.M.; Dunst, J.; Haubner, A.; Durek, P.; Heinrich, F.; Gasparoni, G.; Babic, M.; Tomic, A.; et al. Peptide-specific recognition of human cytomegalovirus strains controls adaptive natural killer cells. Nat. Immunol. 2018, 19, 453-463. [CrossRef]

56. Rolle, A.; Jager, D.; Momburg, F. HLA-E Peptide Repertoire and Dimorphism-Centerpieces in the Adaptive NK Cell Puzzle? Front. Immunol. 2018, 9, 2410. [CrossRef]

57. Rolle, A.; Meyer, M.; Calderazzo, S.; Jager, D.; Momburg, F. Distinct HLA-E Peptide Complexes Modify Antibody-Driven Effector Functions of Adaptive NK Cells. Cell Rep. 2018, 24, 1967-1976. [CrossRef]

58. Boudreau, J.E.; Hsu, K.C. Natural Killer Cell Education and the Response to Infection and Cancer Therapy: Stay Tuned. Trends Immunol. 2018, 39, 222-239. [CrossRef]

59. Horowitz, A.; Djaoud, Z.; Nemat-Gorgani, N.; Blokhuis, J.; Hilton, H.G.; Beziat, V.; Malmberg, K.J.; Norman, P.J.; Guethlein, L.A.; Parham, P. Class I HLA haplotypes form two schools that educate NK cells in different ways. Sci. Immunol. 2016, 1. [CrossRef]

60. Nattermann, J.; Feldmann, G.; Ahlenstiel, G.; Langhans, B.; Sauerbruch, T.; Spengler, U. Surface expression and cytolytic function of natural killer cell receptors is altered in chronic hepatitis C. Gut 2006, 55, 869-877. [CrossRef]

61. Moser, J.M.; Gibbs, J.; Jensen, P.E.; Lukacher, A.E. CD94-NKG2A receptors regulate antiviral CD8(+) T cell responses. Nat. Immunol. 2002, 3, 189-195. [CrossRef]

62. Moser, J.M.; Byers, A.M.; Lukacher, A.E. NK cell receptors in antiviral immunity. Curr. Opin. Immunol. 2002, 14, 509-516. [CrossRef]

63. Byers, A.M.; Kemball, C.C.; Andrews, N.P.; Lukacher, A.E. Regulation of antiviral CD8+ T cells by inhibitory natural killer cell receptors. Microbes Infect. 2003, 5, 169-177. [CrossRef]

64. Byers, A.M.; Andrews, N.P.; Lukacher, A.E. CD94/NKG2A expression is associated with proliferative potential of CD8 T cells during persistent polyoma virus infection. J. Immunol. 2006, 176, 6121-6129. [CrossRef]

65. Wagner, B.; da Silva Nardi, F.; Schramm, S.; Kraemer, T.; Celik, A.A.; Durig, J.; Horn, P.A.; Duhrsen, U.; Nuckel, H.; Rebmann, V. HLA-E allelic genotype correlates with HLA-E plasma levels and predicts early progression in chronic lymphocytic leukemia. Cancer 2017, 123, 814-823. [CrossRef]

(C) 2019 by the authors. Licensee MDPI, Basel, Switzerland. This article is an open access article distributed under the terms and conditions of the Creative Commons Attribution (CC BY) license (http://creativecommons.org/licenses/by/4.0/). 